\title{
Varicocele, wat moet je ermee? Een overzicht van evidence based informatie en controverse als basis voor een goed gesprek
}

\author{
Marij Dinkelman-Smit
}

Geaccepteerd op: 14 januari 2022 / Published online: 8 februari 2022

(C) The Author(s) 2022

\begin{abstract}
Samenvatting In dit overzichtsartikel wordt de relatie besproken tussen een varicocele, mannelijke subfertiliteit, kans op een kind met en zonder behandeling van de varicocele na natuurlijke conceptie of geassisteerde voortplanting. Er wordt kort ingegaan op de verschillende theorieën over de pathofysiologie van de varicocele. Daarnaast worden de klinische diagnose en de overwegingen besproken rond de selectie en indicatiestelling bij subfertiele mannen, kinderen en adolescenten met een varicocele, en bij mannen met klachten en hypogonadisme. Tot slot worden de verschillende behandeltypen, uitkomst, recidief en evaluatie van het effect van interventies doorgenomen.
\end{abstract}

Trefwoorden varicocele mannelijke subfertiliteit . geassisteerde voortplanting $\cdot$ niet-obstructieve azoöspermie $\cdot$ hypogonadisme

\section{How about varicocele? An overview of evidence based information and controversy as a good foundation for a solid conversation}

\begin{abstract}
In this overview, the association between varicocele, male infertility, live birth rate following natural conception or assisted reproduction in men with a treated or untreated varicocele is discussed. Theories concerning the pathophysiology of varicocele are summarized. Clinical diagnosis and considerations regarding patient selection and treatment indication in males with infertility, symptoms, hypogonadism and children and adolescents with varicocele are critically appraised. Finally, the various treatment
\end{abstract}

Dr. M. Dinkelman-Smit $(\bowtie)$

afdeling Urologie Erasmus MC, Universitair Medisch

Centrum Rotterdam, Rotterdam, Nederland

m.smit.3@erasmusmc.nl modalities, including efficacy in terms of outcome and recurrence and evaluation of effect are discussed.

Keywords Varicocele $\cdot$ Male infertility $\cdot$ Assisted reproduction · Non-obstructive azoospermia . Hypogonadism

\section{Introductie}

Een varicocele is een cluster van gedilateerde, tortueuze venen van de plexus pampiniformis, in de funiculus. De incidentie van varicocele bij vruchtbare mannen is $15 \%$, bij mannen met primaire infertiliteit $35-44 \%$ [1], bij mannen met secundaire infertiliteit 45-81\% [2] en bij mannen met azoöspermie 5-15\%. In een multicenter studie van de WHO onder 9.034 mannen die een voortplantingscentrum bezochten in verband met uitblijven van zwangerschap na ten minste 1 jaar proberen, werd bij $11,7 \%$ van de mannen met normospermie een varicocele vastgesteld. Bij $25,4 \%$ van de mannen met afwijkende semenanalyse werd een varicocele gevonden [3]. Om een goed beeld te krijgen van het voorkomen van een varicocele in nietgeselecteerde mannen, werd onder 7.035 jonge mannen van gemiddeld 19 jaar uit Denemarken, Finland, Duitsland, Estland, Letland en Litouwen andrologisch onderzoek verricht bij de intrede in militaire dienst. In dit cross-sectionele onderzoek werd bij $15,7 \%$ van deze mannen een klinisch palpabele varicocele vastgesteld. De aanwezigheid van een varicocele was negatief geassocieerd met de semenkwaliteit en positief met verhoging van het follikelstimulerend hormoon (FSH) en luteïniserend hormoon (LH) [4].

Enerzijds kan geconcludeerd worden dat niet alle varicoceles een negatieve invloed hebben op een van de functies van de testis, de spermatogenese, aangezien de varicocele ook voorkomt bij bewezen vruchtbare mannen. Anderzijds is er een duidelijke 
relatie tussen varicocele, onvervulde kinderwens en afwijkende testisfunctie. Bovendien suggereert de hoge incidentie van varicocele bij mannen die eerder probleemloos een zwangerschap tot stand brachten, secundaire infertiliteit, een progressief negatieve invloed van een varicocele op de testisfunctie.

\section{Pathofysiologie van de varicocele}

De exacte pathofysiologie van de varicocele is onbegrepen, maar omvat theorieën rond verhoogde veneuze druk bij klepinsufficiënte. Dat varicocele voornamelijk linkszijdig voorkomt, correspondeert met meer risico op verhoogde veneuze druk links bij niet continue instroom van de vena spermatica in de vena cava, zoals rechts, maar intredehoek in de vena renalis links van $90^{\circ}$. Veneuze reflux zou resulteren in dilatatie en hydrostatische drukverhoging in de veneuze plexus, met als gevolg verhoogde testiculaire temperatuur, interstitieel oedeem en vertraagde afvloed van toxische metabolieten, welke de testisfunctie beiderzijds negatief beïnvloeden. De totale output van testisfunctie links en rechts, uitgedrukt als uitkomst van semenanalyse en serumtestosteronwaarde, is negatief gecorreleerd met een linkszijdige varicocele.

\section{Associatie met DNA-fragmentatie in zaadcellen}

Bij dieper inzoomen op de mechanismen achter afname van kwantiteit en kwaliteit van de spermatogenese, geven testiculaire hypoxie, warmte en reflux aanleiding tot verhoogde zuurstofradicalen (ROS). ROS medieert zaadcel DNA-fragmentatie en apoptose, die beide geassocieerd zijn met afname van het bevruchtend vermogen van de zaadcel [5]. De DNA-fragmentatie-index (DFI) in zaadcellen is een overkoepelende term die gebruikt wordt voor nietroutinematig uitgevoerde, aanvullende onderzoeken in semen, die indirect enkel- en dubbelstrengs DNAbreuken en afwijkende DNA-integriteit in de zaadcel meten. De DFI kan bepaald worden door verschillende assays, waarvan de uitkomsten correleren, maar niet gelijk zijn. De assays leveren verschillende uitkomstmaten op, die geen van alle een absoluut voorspellende waarde hebben voor geboorte van een gezond kind na natuurlijke zwangerschap of geassisteerde voortplanting. Maar er is wel enige bewijslast dat DFI geassocieerd is met een matige kans op natuurlijke zwangerschap, de uitkomst van geassisteerde voortplanting en herhaalde miskramen [6]. Chirurgische varicocelecorrectie is de enige behandeling waarvan is aangetoond dat het de DFI significant kan verlagen [7]. Ook parameters die zijn gerelateerd aan verhoogde DFI, zoals oxidatieve stress en antioxidantcapaciteit in seminaal plasma, verbeteren significant na varicocelectomie [8].

\section{To treat or not to treat}

Toch zijn er nog steeds 'believers' en 'non-believers' van het nut van een varicocelecorrectie bij mannen met kinderwens. De controverse rond het nut van varicocelecorrectie om de kans op zwangerschap en een gezond kind te verhogen, wordt gevoed door tegenstrijdige onderzoeksresultaten, surrogaatuitkomsten, heterogene studies en hoge uitval bij gerandomiseerd onderzoek.

Een Cochrane-review uit 2004 van Evers en Collins concludeerde dat varicocelectomie bij mannen die onderdeel zijn van een paar zonder andere verklaring voor uitblijven van zwangerschap, geen invloed had op de zwangerschapskans [9]. Revisie en metaanalyse van de data van 237 gerandomiseerde patiënten met een as treated analyses liet zien dat de kans op spontane zwangerschap na varicocelecorrectie wel degelijk significant hoger was met $36,4 \%$ bij behandelde patiënten versus $20 \%$ bij onbehandelde patiënten met een follow-up zonder interventie van één jaar [10].

In 2012 herhaalde Cochrane een meta-analyse van 10 studies bij 894 mannen met een varicocele. $\mathrm{Nu}$ was de conclusie dat spontane zwangerschap wel significant hoger was in de behandelde groep, maar de number needed to treat (NNTT) was 17 . De geïncludeerde studies waren van matige kwaliteit: live birth rate werd niet gerapporteerd als uitkomst, enkele studies bevatten ook patiënten met subklinische niet-palpabele varicoceles en mannen met normale uitslag van de semenanalyse voor de interventie [11]. Bij subgroepanalyse van patiënten met een klinischpalpabele varicocele, en met afwijkende zaadcelconcentratie $(<15 \mathrm{M} / \mathrm{ml})$ en/of afwijkende progressieve zaadcelmotiliteit $(<32 \%)$, was de odds ratio (OR) voor spontane zwangerschap na varicocelebehandeling 2,39 (95\%-BI 1,56-3,66) en de NNTT 7 [11].

Bij graad B-kwaliteit van beschikbare bewijslast, bevelen de American Society for Reproductive Medicine (ASRM), de American Urology Association (AUA) en de European Association of Urology (EAU) in hun richtlijnen aan om te overwegen klinische, palpabele, varicoceles te behandelen, bij mannen met afwijkende semenanalyse en geen of corrigeerbare vrouwelijke factoren voor natuurlijke zwangerschap, zonder andere verklaringen voor uitblijven van natuurlijke conceptie na één jaar of langer onbeschermde coïtus [6, 12].

\section{Diagnose klinische varicocele}

De diagnose klinische varicocele wordt gesteld op basis van onderzoek van de funiculus in staande en liggende houding, met en zonder Valsalva. In de richtlijnen wordt de gradering volgens Dubin en Amelar voorgesteld (tab. 1; [13]).

Een klinische, palpabele varicocele correspondeert met een echografisch gemeten veneuze diameter van de plexus pampiniformis van ten minste $3 \mathrm{~mm}$ en 
Tabel 1 Gradering van varicocele volgens Dubin en Ame-

\begin{tabular}{l|l}
$\begin{array}{l}\text { lar [13] } \\
\text { gradering } \\
\text { varicocele }\end{array}$ & bevindingen bij lichamelijk onderzoek \\
\hline subklinisch & $\begin{array}{l}\text { geen palpabele of zichtbare venen in de funiculus of craniaal } \\
\text { of dorsaal van de testis, of scrotum in rust of na Valsalva, in } \\
\text { staande en liggende houding }\end{array}$ \\
\hline graad 1 & palpabele varicocele tijdens Valsalva \\
graad 2 & palpabele varicocele in rust \\
\hline graad 3 & zichtbare en palpabele varicocele in rust
\end{tabular}

$>2$ seconden veneuze reflux bij Valsalva of in rust. Echografisch onderzoek kan ook een intratesticulaire varicocele diagnosticeren, hoewel de meerwaarde hiervan voor klinische besluitvorming onduidelijk is [14].

Oplopende gradering is geassocieerd met slechtere uitkomst van de semenanalyse, waarbij ook reeds bij graad 1-klinische varicocele significant lagere zaadcelconcentratie wordt beschreven, in vergelijking tot mannen zonder varicocele [4]. Een recente systematische review van 20 studies concludeerde echter dat de gemiddelde toename van zaadcelconcentratie en motiliteit in graad 1-varicoceles weliswaar significant was, maar bescheiden, ten opzichte van het effect op verbetering van de semenkwaliteit bij correctie van graad 2- en 3-varicoceles [15].

Klinische diagnosestelling is expertiseafhankelijk, en hoewel echografische bevestiging van een klinische diagnose van een varicocele discutabel is, zijn diverse radiologische definities en graderingssystemen gepubliceerd en gebruikt in studies, en ook samengevat in de richtlijn van de European Society of Urogenital Radiology Scrotal and Penile Imaging Working Group (ESUR-SPIWG) [16]. Voorop blijft staan, dat voor de diagnose van een varicocele uitgegaan moet worden van bevindingen bij lichamelijk onderzoek; een echo scrotum laten doen door de radioloog volstaat niet als methode om een man met kinderwens en afwijkende semenanalyse te beoordelen op corrigeerbare oorzaken van de subfertiliteit.

\section{Bilaterale varicocele}

Bilaterale varicocele wordt met wisselende incidentie beschreven, maar in de praktijk is de diagnose van een klinische, palpabele bilaterale varicocele in mijn ervaring zeldzaam. Damsgaard et al. concludeerden in hun eerder geciteerde cross-sectionele, ongeselecteerde studie dat in hun populatie van 7.035 mannen die in militaire dienst traden bij $1 \%$ een bilaterale klinisch palpabele varicocele werd vastgesteld [4].

Unilaterale rechtszijdige varicocele is zeer zeldzaam en rechtvaardigt beeldvorming van het retroperitoneum en abdomen om verklarende pathologie uit te sluiten (waaronder vena renalis of vena cava trombose, niertumor of retroperitoneale lymfadenopathie).

\section{Behandeling van varicocele}

De keuze voor het type varicocelebehandeling wordt in richtlijnen ofwel aan de uroloog overgelaten, ofwel er wordt met gematigde bewijslijst microchirurgische varicocelectomie aanbevolen. Een meta-analyse van 36 retrospectieve studies concludeerde dat de natuurlijke conceptie na microchirurgische subinguïnale varicocelecorrectie het hoogst is $(42 \%)$ gevolgd door de retroperitoneale ligatie (38\%), macroscopische inguinale varicocelectomie (36\%), embolisatie (33\%) en laparoscopische retroperitoneale ligatie (30\%) [17].

Bij de microchirurgische subinguïnale varicocelecorrectie worden alle venen doorgenomen en een of meerdere arteriën en lymfevaten gespaard. Recidiefpercentages van microchirurgische correctie, laparoscopische correctie, embolisatie en Palomo zijn respectievelijk 1, 4, 13 en $15 \%$. Het risico op postoperatieve hydrocele is met $0,5 \%$ ook het laagste na microchirurgische varicocelecorrectie versus respectievelijk $8 \%$ na Palomo en $3 \%$ na laparoscopische correctie [17].

Toch wordt microchirurgische varicocelecorrectie in Nederland weinig uitgevoerd. Patiënten en behandelaars kiezen vaak voor een stepped-carebehandeling, waarbij radiologische embolisatie de eerste stap is, en microchirurgie alleen bij recidief wordt ingezet. Ook wanneer microchirurgische behandeling wel beschikbaar is in een centrum of regio, schrikt het zeer kleine risico op iatrogeen laederen van de arteria spermatica tijdens microchirurgische correctie, patiënten en ouders van patiënten nogal eens af, waardoor in eerste instantie toch gekozen wordt voor embolisatie of retroperitoneale ligatie.

\section{Effect van een interventie evalueren}

Nacontrole om een recidiefvaricocele uit te sluiten en herhaalde semenanalyse drie en zes maanden postoperatief zijn essentieel om het herstelpotentieel van de spermatogenese te kunnen beoordelen. In een Chinese studie was de gemiddelde tijd tot natuurlijke zwangerschappen na varicocelecorrectie 11,7 maanden [18].

De uitkomst van postoperatieve semenanalyse en oriënterend fertiliteitsonderzoek van de vrouw geven richting aan een gewogen advies over de periode van in afwachting blijven van natuurlijke conceptie of overgaan tot geassisteerde voortplanting.

\section{Varicocele bij geassisteerde voortplanting}

De varicocele wordt ook wel beschouwd als aanvullende negatieve factor, bovenop matige testisfunctie en gestoorde spermatogenese door andere causale factoren. In deze 2nd hit- of cofactor-theorie, past het concept van het doorbreken van het progressief negatieve effect van de varicocele op de spermatogenese, en optimaliseren van de DFI, zelfs als geassisteerde 
voortplanting de enige behandeloptie blijft na varicocelecorrectie.

Samplaski et al. beschreven hoe varicocelecorrectie het type geassisteerde voortplanting kan upstagen van IVF/ICSI naar IUI of van ICSI naar IVF [19]. Op grond van een systematische review en meta-analyse uit 2016 over zeven artikelen met in totaal 1.241 patiënten werd geconcludeerd dat de live birth rate na ICSI bij mannen met oligospermie en een gecorrigeerde varicocele significant hoger was ten opzichte van die na ICSI bij mannen met een onbehandelde varicocele [20].

Ook voor deze mogelijke indicatie voor varicocelectomie ontbreekt prospectief, gerandomiseerd onderzoek, maar levert beschikbaar onderzoek interessant indirect bewijs voor mogelijke meerwaarde van varicocelecorrectie bij geselecteerde patiënten met semen van IVF/ICSI-kwaliteit.

\section{Varicocele bij niet-obstructieve azoöspermie (NOA)}

Daarnaast is in retrospectieve studies onderzocht of varicocelectomie bij mannen met NOA resulteert in terugkeer van zaadcellen in het ejaculaat, waardoor testiculaire spermaextractie (TESE) voorkomen kan worden.

Esteves et al. publiceerden in 2016 een meta-analyse van 18 studies met in totaal 468 patiënten en rapporteerden terugkeer van zaadcellen in postoperatieve semenanalyse bij $44 \%$ van de patiënten met NOA, $13,6 \%$ spontane zwangerschappen en $18,9 \%$ zwangerschappen na IVF/ICSI met zaadcellen uit het ejaculaat [21]. Recenter includeerden Elbardisi et al. 23 studies met in totaal 751 mannen met NOA en een varicocele in hun analyse, en concludeerden dat zaadcellen terugkeerden in het ejaculaat bij 222/751 $(29,5 \%)$ van de geopereerde patiënten [22]. Mannen die ten tijde van de varicocelecorrectie ook een TESE ondergingen, met hypospermatogenese en een laat maturatiearrest van spermatiden als uitkomst van de histologische analyse van het testisbiopt, hadden een hogere kans op spermatogenese-inductie na varicocelecorrectie dan mannen met een histologiebeeld van Sertoli Cell only of een vroeg maturatiearrest [23]. Daarnaast stelden diverse andrologieonderzoeksgroepen zich de vraag of de opbrengst van TESE zou verbeteren als de varicocele drie tot zes maanden voorafgaand aan de TESE gecorrigeerd zou worden. De sperm retrieval rate (SRR) bij 42 mannen die voorafgaand aan de TESE een varicocelecorrectie ondergingen was $69 \%$, versus een SRR van $27 \%$ bij 62 mannen bij wie de varicocele ongemoeid werd gelaten [24].

Het mechanisme dat de hier genoemde resultaten mogelijk verklaart, is activatie van inactieve spermatogonia waardoor de minimale zaadcelproductie die focaal voorkomt in het testisparenchym van mannen met NOA toeneemt. Deze inductie van spermatogenese door het negatieve effect van de varicocele weg te nemen, zou zowel de terugkeer van zaadcellen in het ejaculaat als de hogere SRR kunnen verklaren.

Methodologische kritiek is ten eerste dat geen van de studies randomisatie toepasten. Wachttijd voor ART of varicocelectomie, kosten van de ART voor rekening van de patiënt, leeftijd van de vrouw, voorkeur van de uroloog om chirurgisch te behandelen, kunnen alle bijgedragen hebben aan een onevenwichtige patiëntverdeling over de geopereerde versus nietgeopereerde cohorten.

Bovendien zijn de studies heterogeen in het type toegepaste varicoceletechniek en het tijdsinterval tussen de interventie, de effectevaluatie en de gerapporteerde uitkomstmaten. In het algemeen worden factoren die relevant zijn voor de uitkomst van TESE en TESE-ICSI zeer inconsistent gerapporteerd in de literatuur. Zo wordt kwantitatieve en kwalitatieve informatie over de SRR zelden beschreven en zijn klinischrelevante uitkomsten als live birth rate vaak niet de uitkomstmaten van studies [25]. Dit geldt ook voor de literatuur die de invloed van varicocelecorrectie bij patiënten met NOA op de uitkomst van TESE en TESEICSI evalueren.

Daarnaast is de oorzaak van NOA multifactorieel en wordt deze in ten minste $30 \%$ van de gevallen toegeschreven aan nog onbekende, genetische en epigenetische factoren. Vanuit theoretisch perspectief is het onwaarschijnlijk dat een varicocele in geval van een genetisch verklaarde ernstig afwijkende spermatogenese, een significant onderdeel zal uitmaken van de corrigeerbare oorzaken van NOA.

Tot slot is het bekend dat de concentratie zaadcellen per ejaculaat bij gezonde mannen sterk kan variëren in de tijd [3]. Voor mannen met azoöspermie geldt ook dat absolute azoöspermie, gedefinieerd als geen zaadcellen in pelletonderzoek na centrifugatie van het ejaculaat, en cryptozoöspermie, gedefinieerd als minder dan 100.000 zaadcellen per milliliter ejaculaat, zich vaak in de tijd afwisselen. Selectiebias is aanwezig bij het merendeel van de studies naar het effect van varicocelecorrectie op inductie van spermatogenese, aangezien patiëntinclusie gebaseerd wordt op slechts één semenanalyse en NOA niet altijd gedefinieerd of vastgesteld wordt op basis van centrifugatie en pelletonderzoek.

Bij gebrek aan gecontroleerd onderzoek wordt varicocelecorrectie bij patiënten met NOA niet meer als te overwegen aanbevolen in richtlijnen.

\section{Kinderen en adolescenten met een varicocele}

Meerdere studies toonden aan dat toenemende gradering van de klinische varicocele een significante afname geeft van het testisvolume [3, 4]. In lijn met deze theorie is het achterblijven van testisvolume links een belangrijk symptoom waarop correctie van een klinische varicocele bij adolescenten kan worden overwogen. 


\title{
Hier staat een advertentie.
}

\author{
$c$ bohn

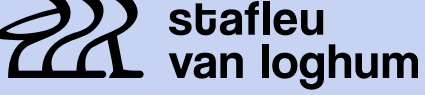 \\ Springer Media
}

Houten 2021 


\title{
Hier staat een advertentie.
}

\author{
$c$ bohn

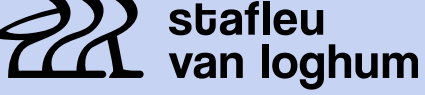 \\ Springer Media
}

Houten 2021 
De behandeling van klinische varicocele bij kinderen en adolescenten is controversieel. Een systematische review en meta-analyse onder auspiciën van de guidelinepanels van de EAU en de European Society for Paediatric Urology (ESPU) concludeerde, op basis van 16.130 patiënten tussen 7 en 21 jaar oud, dat varicocelecorrectie verbetering geeft van testisvolume en totaal aantal zaadcellen in vergelijking tot afwachten. Bij gebrek aan langdurige follow-up, kon geen uitspraak gedaan worden over het langetermijneffect op vaderschapskans [26]. De aanbevelingen voor de patiëntselectie voor interventie blijven: hooggradige varicocele, achterblijvend testisvolume links (ten minste $20 \%$ kleiner dan rechts of verschil $>2 \mathrm{ml}$ ), bijkomende cryptorchisme of torsio testis, pijn en afwijkende semenanalyse worden genoemd in de EAU Guidelines on paediatric urology. Benadrukt moet worden dat het confronteren van jongvolwassenen met een afwijkende uitslag van een semenanalyse om zorgvuldige begeleiding vraagt.

\section{Symptomen: pijn en cosmetiek}

Symptomen van een varicocele zijn pijn en een zichtbare zwelling craniaal en/of lateraal, dorsaal van de testis, wisselend in grootte, afhankelijk van staande houding of lichamelijke activiteit. Pijn of ongemak worden beschreven door $2-10 \%$ van de mannen met een varicocele. Scherpe pijn geeft een slechtere resolutie na behandeling dan doffe pijn [27]. Na varicocelectomie verdwijnt de pijn bij $48-90 \%$ van de patiënten [28].

Het is belangrijk pijnklachten goed uit te vragen om een causaal verband tussen de klachten en de varicocele vast te stellen. Klachten van disfunctionele mictie, aan bekkenbodemhypertonie gerelateerde klachten, urgency, frequency en orchialgie komen regelmatig voor bij mannen bij wie ook een varicocele wordt vastgesteld.

Daarnaast is het verstandig om verwachtingen ten aanzien van postoperatieve pijnklachten te bespreken. Passagièregevoeligheid van de testis bij aanraking na varicocelectomie wordt vaak gemeld door patiënten met een verder ongestoord postoperatief herstel. Bij slechts een paar procent van de patiënten treedt de novo persisterende pijn of irreversibele gevoeligheid van de testis op.

Ontsierende venentekening of scrotale zwelling nemen in de loop van de maanden na de behandeling af als iatrogene hydrocele is uitgesloten. Patiënten nemen vaak aan dat de venen worden verwijderd bij chirurgische behandeling. Het loont de moeite om bij het informed consent voor de ingreep het verwachte postoperatieve beloop van stase, trombose en samenvallen van de venen toe te lichten.

\section{Varicocele en hypogonadisme}

In de eerder geciteerde Europese studie onder 7.035 gezonde jonge militairen, was een klinisch vastgestelde varicocele geassocieerd met verhoogd FSH en LH, maar niet met testosteron of serumwaarden van vrij testosteron, in vergelijking tot mannen zonder varicocele [4]. Het verhoogde LH bij jonge mannen met een varicocele, kan uitgelegd worden als reeds gecompenseerde testisfunctie. Met andere woorden, om tot vergelijkbare testosteronwaarden te komen als bij controlemannen zonder varicocele is meer LHafgifte door de hypofyse en stimulatie van de Leydigcellen nodig.

De multicenterstudie van de WHO toonde een significant lager testosterongehalte aan bij infertiele mannen ouder dan 30 jaar met een varicocele in vergelijking met jongere infertiele mannen met een varicocele [3]. De progressieve achteruitgang van de functie van de Leydig-cellen onder invloed van een varicocele lijkt reversibel. Chen et al. toonden een significante toename aan in postoperatieve testosteronwaarden bij mannen met hypogonadisme die behandeld werden voor een varicocele [29].

Een mogelijke rol voor varicocelecorrectie bij de behandeling van symptomatisch hypogonadisme, of als preventieve behandeling ter voorkoming van progressieve achteruitgang van testosteronproductie is vooralsnog niet helder beschreven in richtlijnen.

\section{Afsluitend betoog}

Concluderend is een multidisciplinaire indicatiestelling met gynaecologen die zijn gespecialiseerd in voortplantingsgeneeskunde voor varicocelebehandeling bij kinderwens aan te bevelen. De uitkomsten van volledig andrologisch (lichamelijk) onderzoek en het oriënterend fertiliteitsonderzoek van de vrouw geven richting aan de inhoud en overwegingen van de counseling van het paar.

Mijns inziens wordt in Nederland nog te vaak de diagnose van een varicocele niet of pas na mislukte IVF-pogingen gesteld. Daarnaast wordt counseling van de man over de mogelijke negatieve effecten van de varicocele voor testisfunctie, inclusief testosteronproductie, en de voor- en nadelen van varicocelebehandeling in het geheel niet of niet evenwichtig uitgevoerd.

In mijn ervaring kunnen patiënten en hun partners uitstekend zelf een geïndividualiseerde beslissing nemen over een eventuele behandeling van de varicocele, inclusief de techniek en timing ervan, maar alleen nadat de beschikbare medische kennis, inclusief onzekere of matig-sterke informatie over de bewijslast, door de behandelend uroloog met hen is besproken. Ik doe hierbij een dringende oproep om in ieder ziekenhuis waar voortplantingsgeneeskunde bedreven wordt, de samenwerking tussen gynaecologen, fertiliteitsartsen en urologen te versterken en kennis 
en kunde rond de diagnose en behandeling van de varicocele te verhogen.

Open Access This article is distributed under the terms of the Creative Commons Attribution 4.0 International License (http://creativecommons.org/licenses/by/4.0/), which permits unrestricted use, distribution, and reproduction in any medium, provided you give appropriate credit to the original author(s) and the source, provide a link to the Creative Commons license, and indicate if changes were made.

\section{Literatuur}

1. Jensen CFS, Ostergren P, Dupree JM, Ohl DA, Sonksen J, Fode M. Varicocele and male infertility. Nat Rev Urol. 2017;14(9):523-33.

2. Gorelick JI, Goldstein M. Loss of fertility in men with varicocele. Fertil Steril. 1993;59(3):613-6.

3. World Health Organization. The influence of varicocele on parameters of fertility in a large group of men presenting to infertility clinics. Fertil Steril. 1992;57(6):1289-93.

4. Damsgaard J, Joensen UN, Carlsen E, et al. Varicocele is associated with impaired semen quality and reproductive hormone levels: a study of 7035 healthy young men from six European countries. Eur Urol. 2016;70(6):1019-29.

5. Panner Selvam MK, Agarwal A. Sperm and seminal plasma proteomics: molecular changes associated with varicocele-mediated male infertility. World J Mens Health. 2020;38(4):472-83.

6. Minhas S, BettocchiC, BoeriL, etal. European association of urology guidelines on male sexual and reproductive health: 2021 update on maleinfertility. Eur Urol. 2021;80(5):603-20.

7. Baazeem A, Belzile E, Ciampi A, et al. Varicocele and male factor infertility treatment: a new meta-analysis and review of theroleofvaricocelerepair. EurUrol. 2011;60(4):796-808.

8. Chen SS, Huang WJ, Chang LS, Wei YH. Attenuation of oxidative stress after varicocelectomy in subfertile patients with varicocele. J Urol. 2008;179(2):639-42.

9. EversJL, Collins JA. Surgeryor embolisation forvaricocelein subfertilemen. Cochrane DatabaseSystRev. 2004;3:CD479.

10. Ficarra V, Cerruto MA, Liguori G, et al. Treatment of varicocele in subfertile men: the cochrane review-a contrary opinion. Eur Urol. 2006;49(2):258-63.

11. Kroese AC, Lange NM de, Collins J, Evers JL. Surgery or embolization for varicoceles in subfertile men. Cochrane Database Syst Rev. 2012;10:CD479.

12. Schlegel PN, Sigman M, Collura B, et al. Diagnosis and treatment of infertility in men: AUA/ASRM guideline PART II. J Urol. 2021;205(1):44-51.

13. DubinL,Amelar RD. Reprint of: varicocelesizeandresults of varicocelectomy in selected subfertile men with varicocele. FertilSteril. 2019;112(4):e57-e60.

14. Lotti F, Frizza F, Balercia G, et al. The European academy of andrology (EAA) ultrasound study on healthy, fertile men: scrotal ultrasound reference ranges and associations with clinical, seminal, and biochemical characteristics. Andrology. 2021;9(2):559-76.

15. Asafu-AdjeiD,JudgeC,DeibertCM,LiG,StemberD, StahlPJ. Systematic review of the impact of varicocele grade on response to surgical management. J Urol. 2020;203(1):48-56.
16. Freeman S, Bertolotto M, Richenberg J, et al. Ultrasound evaluation of varicoceles: guidelines and recommendations of the European society of urogenital radiology scrotal and penile imaging working group (ESUR-SPIWG) for detection, classification, and grading. Eur Radiol. 2020;30(1):11-25.

17. Cayan S, Shavakhabov S, Kadioglu A. Treatment of palpable varicocele in infertile men: a meta-analysis to define the best technique. JAndrol. 2009;30(1):33-40.

18. Peng J, Zhang Z, Cui W, et al. Spontaneous pregnancy rates in Chinese men undergoing microsurgical subinguinal varicocelectomy and possible preoperative factors affecting the outcomes. FertilSteril. 2015;103(3):635-9.

19. Samplaski MK, Lo KC, Grober ED, Zini A, Jarvi KA. Varicocelectomy to "upgrade" semen quality to allow couples to use less invasive forms of assisted reproductive technology. Fertil Steril. 2017;108(4):609-12.

20. Kirby EW, Wiener LE, Rajanahally S, Crowell K, Coward RM. Undergoing varicocele repair before assisted reproduction improves pregnancy rate and live birth rate in azoospermic and oligospermic men with a varicocele: a systematic review and meta-analysis. Fertil Steril. 2016;106(6):1338-43.

21. Esteves SC, Miyaoka R, Roque M, Agarwal A. Outcome of varicocele repair in men with nonobstructive azoospermia: systematic review and meta-analysis. Asian J Androl. 2016;18(2):246-53.

22. Elbardisi H, ElAnsariW, Majzoub A, Arafa M. Does varicocelectomyimprove semen in men with azoospermia and clinically palpable varicocele? Andrologia. 2020;52(2):e13486.

23. Shiraishi K, Oka S, Matsuyama H. Predictive factors for sperm recovery after varicocelectomy in men with nonobstructive azoospermia. JUrol. 2017;197(2):485-90.

24. Birowo P, Prasetyo DT, Pujianto DA, Atmoko W, Rasyid N, Sini IR. Effect of varicocele repair on sperm retrieval rate and testicular histopathological patterns in men with nonobstructive azoospermia. Asian J Androl. 2022;24(1):85-9. https://doi.org/10.4103/aja.aja_29_21.

25. Ernandez J, Berk B, Han T, Abou Ghayda R, Kathrins M. Evaluating the quality of reported outcomes for microsurgical TESE in men with non-obstructive azoospermia: a methodological analysis. Andrology. 2021;9(4):1108-18.

26. Silay MS, Hoen L, Quadackaers J, et al. Treatment of varicocele in children and adolescents: a systematic review and meta-analysis from the European association of urology/ European society for paediatric urology guidelines panel. Eur Urol. 2019;75(3):448-61.

27. Han DY, Yang QY, Chen X, et al. Who will benefit from surgical repair for painful varicocele: a meta-analysis. Int Urol Nephrol. 2016;48(7):1071-8.

28. Baek SR, Park HJ, Park NC. Comparison of the clinical characteristics of patients with varicocele according to the presence or absence of scrotal pain. Andrologia. 2019;51(2):e13187.

29. Chen X, Yang D, Lin G, Bao J, Wang J, Tan W. Efficacy of varicocelectomy in the treatment of hypogonadism in subfertile males with clinical varicocele: a meta-analysis. Andrologia. 2017; https://doi.org/10.1111/and.12778.

Dr. Marij Dinkelman-Smit, uroloog, EAA gecertificeerd klinisch androloog 